\title{
PRIEŠOPERACINIO MOKYMO POVEIKIS PACIENTU PO PRIEKINIO KRYŽMINIO RAIŠČIO PLASTIKOS FUNKCINEI BŪKLEI
}

\author{
Aistė Vainiūtè $\dot{e}^{1,2}$, Ieva Eglè Jamontaitè $\dot{e}^{1,2}$ \\ ${ }^{1}$ Vilniaus universiteto Medicinos fakulteto Reabilitacijos, fizinès ir sporto medicinos katedra, \\ ${ }^{2} V$ Vilniaus universiteto ligoninès Santariškiu kliniku Reabilitacijos, fizinès ir sporto medicinos \\ centras
}

Raktažodžiai: priekinio kryžminio raiščio plastika, pacientų mokymas, funkcinè būklè.

\begin{abstract}
Santrauka
Tyrimo tikslas - ivvertinti priešoperacinio mokymo poveiki pacientų po priekinio kryžminio raiščio (PKR) plastikos funkcinei būklei. Tyrime dalyvavo 21 pacientas (amžius 32,9 9,9,99 metai). Tiriamieji atsitiktinés atrankos būdu buvo suskirstyti ị dvi grupes: tiriamają, kuriai taikytas išsamus priešoperacinis mokymas ir pateikta rekomenduojama namų pratimų programa, ir kontrolinę, kuri gavo trumpą žodinį mokymą ir parengtą ịprastinę atmintinę. Klinikinių rodiklių matavimas buvo atliktas prieš dieną iki PKR plastikos ir ménuo po jos. Duomenys apskaičiuoti taikant Stjudent'o (t) kriterijų, reikšmingumo lygmuo $\mathrm{p}<0,05$. Mènuo po PKR plastikos abiejų grupių tiriamųjų funkcinè būklè pablogèjo, tačiau tiriamosios grupès subjektyvios kelio sąnario būklès, tiesimo ir lenkimo amplitudès, skausmo, patinimo, šlaunies ir blauzdos raumenų hipotrofijos, izometrinè blauzdos lenkiamujų ir tiesiamujų raumenų jẻgos vertinimo rezultatai buvo geresni nei kontrolinès.
\end{abstract}

\section{Ivadas}

JAV PKR traumos sudaro iki 50\% visų kelio sąnario traumų, apskaičiuota, kad jų dažnis yra 6,5 PKR traumos 10000 sportininkų. Maždaug 90 proc. pacientų, kurie siekia gydytis PKR plyšimus, atliekama PKR plastika [1]. PKR traumos paplitimas dažniausiai pastebimas jaunoje 15 - 25 metų populiacijoje, ypač dèl vis didejjančio susidomejjimo populiariomis sportinèmis veiklomis, kurios reikalauja stiprių, tikslių ir kontroliuojamų judesių, kur PKR labai svarbus užtikrinant kelio sąnario stabilumą [2]. Nuplyšus PKR asmenų fizinis aktyvumas ženkliai sumažeja, atsiranda nepasitikejimas savo judejimo galimybèmis, o dèl to blogèja jų gyvenimo kokybè [3]. Siekiant kuo labiau sumažinti traumos sukeliamas pasekmes daugumai aktyvių žmonių rekomenduojama PKR plastika ir ankstyva pooperacinè reabilitaciją, kurios pagrindinis tikslas yra atstatyti asmenų funkcinę būklę: amplitudes, mažinti skausmą, tinimą, hipotrofiją, didinti raumenų jègą bei kartu apsaugoti transplantatą pooperacinès remodeliacijos fazeje [2-4]. Tačiau nustatyta, kad dažnai po PKR rekonstrukcijos pacientams trūksta motyvacijos prisidèti prie savo būklès gerinimo, o motyvacija yra sukuriama ir palaikoma trimis būdais: tikslų nustatymu, kartotiniu funkciniu testavimu bei kvalifikuotu prieš arba pooperaciniu pacientų mokymu [5].

Dėmesys priešoperaciniam mokymui eksperimentiniuose tyrimuose per pastaruosius tris dešimtmečius labai padidejo. Ronco ir kt., Grindem ir kt. straipsniuose teigiama, kad priešoperacinis mokymas turi įtakos sumažejjusiam nerimui ir skausmui, greitesniam kelio sąnario funkcijų atkūrimui bei psichologinei gerovei ir pacientu pasitenkinimui iškart po chirurginès intervencijos $[5,6]$. Daugelyje moksliškai pagristų gydymo programų, kalbant apie pooperacinę PKR reabilitaciją, iškeliami tikslai siekti pacientų sąmoningumo ir greitesnio jų funkcinès būklès atsistatymo taikant priešoperacinį mokymą [2, 7]. Malempati ir kt. (2015) pateikia reabilitacijos programos modeli, kuriame mokymo pagrindinis tikslas siekti, kad pacientas po PKR traumos suprastų pagrindinius priešoperacinius ir ankstyvo pooperacinio gydymo principus bei būtų supažindintas su namų reabilitacijos programa [7]. Deja, nors priešoperacinis mokymas pasaulyje po PKR traumos yra skatinamas, vis dar trūksta pagrịstų ịrodymais tyrimų apie jo naudą pacientų funkcinei būklei.

Tyrimo tikslas - ịvertinti priešoperacinio mokymo poveiki pacientu po priekinio kryžminio raiščio plastikos funkcinei būklei.

\section{Tyrimo objektas ir metodika}

Tyrimas atliktas Vilniaus universiteto ligoninès Santariš- 
kių klinikų Ambulatorinès reabilitacijos skyriuje nuo 2015 $\mathrm{m}$ rugsėjo iki $2016 \mathrm{~m}$ balandžio ménesio. Tyrime dalyvavo 28 pacientai, tyrimą baige 21 ( 7 atkrito, nes: 1 - atsisakè sugrižti, 2 - negalejjo atvykti iš kito miesto, 2 - negalëjo atvykti derinamu laiku; 1 - atidejo operaciją; 1 - atvyko vèliau). Vidutinis tiriamujų amžius buvo $32,9 \pm 9,99$ metai.

Pacientu įtraukimo i tyrimą kriterijai: pirmą kartą patirtas PKR plyšimas bei suplanuota PKR plastiką. Neįtraukimo i tyrimą kriterijai: pakartotinè kelio sąnario trauma, PKR plyšimas kartu su meniskų/o ar kitų kelio sąnarị supančių struktūrų pažeidimu, gretutinès ligos, galinčios sutrukdyti tyrimui (pvz., epilepsija).

Subjektyviai kelio sąnario funkcinei būklei vertinti buvo naudojamas Lysholm klausimynas, skausmui - 10 balų vizualinè analogijos skausmo skalè (VAS), patinimui ịvertinti - kelio sąnario apimties matavimas (cm), pažeistos kojos šlaunies ir blauzdos raumenu hipotrofijai nustatyti - jų apimčių matavimas (cm), sveikos ir pažeistos kojos blauzdos lenkiamųjų ir tiesiamujų raumenų izometrinès jègos matavimui - „Lafayette“ rankinis dinamometras. Tiriamujų ūgis ir svoris buvo matuojami remiantis PSO rekomendacijomis, apskaičiuotas ir kūno masès indeksas (KMI).

Tiriamieji atsitiktinès atrankos būdu buvo suskirstyti ì dvi grupes: kontrolinę, kuri gavo trumpą žodinị mokymą, ir parengtą ịprastinę atmintinę bei tiriamają - jai buvo pateikta power point paruošta prezentacija apie PKR, jo biomechaniką ir funkciją, traumos epidemiologiją ir etiologiją, plyšimo pasekmes, plastikos naudą ir pasekmes po

1 lentelė. Tiriamujų bendra charakteristika

\begin{tabular}{|l|c|c|c|}
\hline \multirow{2}{*}{ Rodikliai } & \multicolumn{3}{|c|}{ Rezultatų vidurkis \pm SN } \\
\cline { 2 - 4 } & $\begin{array}{c}\text { Tiriamoji } \\
(\mathbf{n}=\mathbf{1 1})\end{array}$ & $\begin{array}{c}\text { Kontrolinė } \\
(\mathbf{n}=\mathbf{1 0})\end{array}$ & $\mathbf{p}$ \\
\hline Amžius & $30,64 \pm 9,11$ & $34,1 \pm 11,07$ & 0,447 \\
\hline Ūgis $(\mathrm{cm})$ & $1,81 \pm 0,07$ & $1,78 \pm 0,08$ & 0,309 \\
\hline Svoris $(\mathrm{kg})$ & $85,63 \pm 19,03$ & $85,30 \pm 16,79$ & 0,966 \\
\hline KMI & $25,96 \pm 4,64$ & $27,06 \pm 5,16$ & 0,972 \\
\hline
\end{tabular}

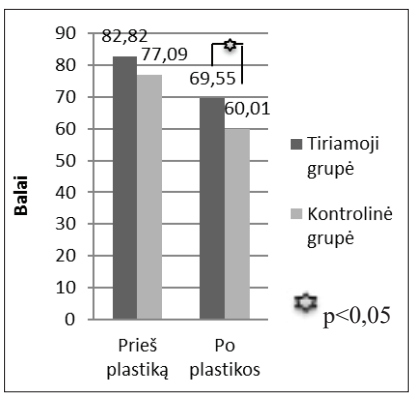

1 pav. "Lysholm" klausimyno rezultatai

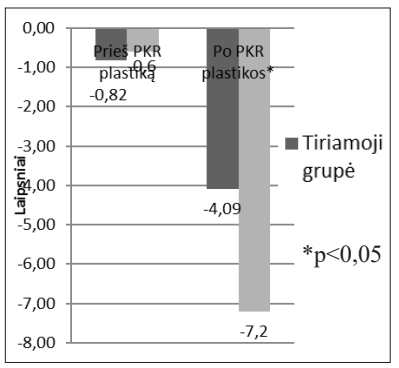

2 pav. Kelio sąnario tiesimo amplitudès. jos bei buvo pristatomi pagrindiniai reabilitacijos tikslai ir remiantis moksliniuose šaltiniuose pateikiamais reabilitacijos protokolais rekomenduojamas pratimu kompleksas, skirtas funkcinei būklei gerinti namuose pirmajị mėnesị po PKR plastikos: izometriniai pratimai keturgalviui, užpakaliniams šlaunies ir blauzdos raumenims (8-10 k. po 5-10 s, $2-3$ serijos ne $<3 \mathrm{k} . / \mathrm{d}$.); pagalvèlès paspaudimai po keliu/ kulnu/tarp kelių; tiesios kojos kèlimas, atitraukimas, tiesimas (8-10 k. po $2-3$ serijas, ne $<3 \mathrm{k} . / \mathrm{d}$.); aktyvūs pratimai lenkiant kelio sąnari (pvz., kulno slydimas); svorio pernešimo pratimai. Palaipsniui kartojimų ar serijų skaičių siūlyta didinti. Mokymai vyko dieną prieš PKR plastiką kiekvienam tiriamajam asmeniškai, eigoje buvo galima klausinèti. Pristatyta medžiaga buvo nusiųsta pacientams. Jie taip pat buvo skatinami bendradarbiauti, jei iškildavo klausimų.

Statistinè duomenų analizè buvo atliekama naudojant kompiuterinès programos statistikos „R x64 3.0.3“ ir „Micrsoft Office Excel 2010" skaičiavimo programas. Skaičiuoti rodiklių aritmetiniai vidurkiai \pm standartinis nuokry-

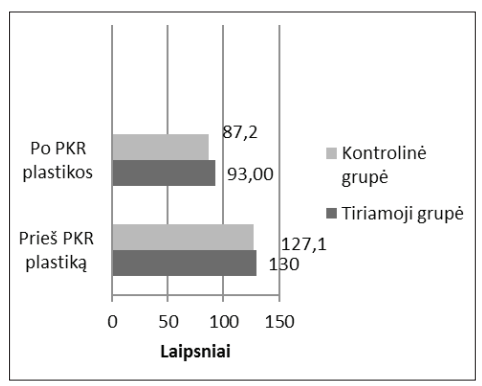

3 pav. Kelio sąnario lenkimo amplitudès

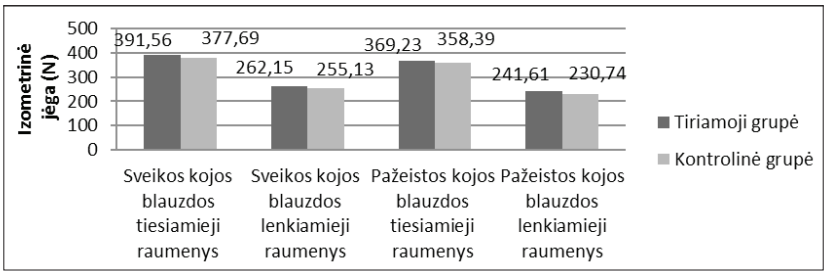

4 pav. Izometrinè blauzdos lenkiamujjų ir tiesiamųjų raumenų jèga prieš PKR plastiką

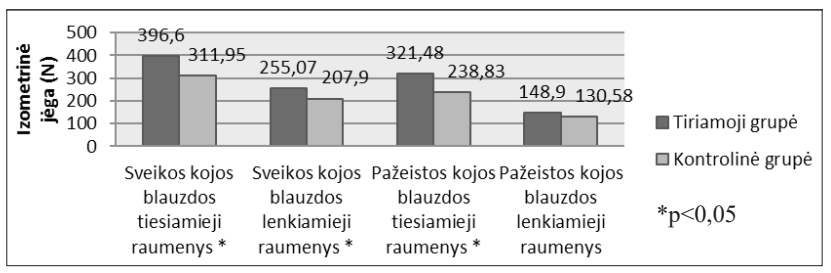

5 pav. Izometrinè blauzdos lenkiamujų ir tiesiamųų raumenų jèga praèjus mènesiui po PKR plastikos 
pis ir patikrintas statistinis reikšmingumas. Jei duomenys tenkino normalumą, jie apskaičiuoti pagal Stjudent'o t kriterijų, jei netenkino - pagal Vilkoksono ženklų kriterijų. Abiem atvejais, jei $\mathrm{p}<0,05$ - skirtumas laikomas statistiškai reikšmingu.

\section{Rezultatai ir jų aptarimas}

2 lentelè. Skausmo rodiklis prieš ir po PKR plastikos $\pm S N- \pm$ standartinis nuokrypis; $p^{* *}$ - reikšmingumas tarp grupiu; $p^{*}$ - reikšmingumas grupèse.

\begin{tabular}{|l|c|c|c|}
\hline Grupès & $\begin{array}{c}\text { Prieš PKR } \\
\text { plastiką } \\
\text { (Vidurkis } \pm \text { SN) }\end{array}$ & $\begin{array}{c}\text { Po PKR plas- } \\
\text { tikos } \\
\text { (Vidurkis } \pm \text { SN) }\end{array}$ & $\mathrm{p}^{*}$ \\
\hline $\begin{array}{l}\text { Tiriamoji } \\
(\mathrm{n}=11)\end{array}$ & $1,1 \pm 1,78$ & $0,64 \pm 0,81$ & $\mathrm{p}>0,05$ \\
\hline $\begin{array}{l}\text { Kontroline } \\
(\mathrm{n}=10)\end{array}$ & $1 \pm 1,41$ & $2,1 \pm 0,94$ & $\mathbf{p}<\mathbf{0 , 0 5}$ \\
\hline $\mathbf{p}^{* *}$ & $\mathrm{p}>0,05$ & $\mathbf{p}<\mathbf{0 , 0 5}$ & \\
\hline
\end{tabular}

3 lentelè. Pažeistos kojos kelio sąnario apimties rodikliai $(\mathrm{cm})$ prieš ir po PKR plastikos

$\pm S N$ - \pm standartinis nuokrypis; $p^{* *}$ - reikšmingumas tarp grupiu; $p^{*}$ - reikšmingumas grupése.

\begin{tabular}{|l|c|c|c|}
\hline Grupės & $\begin{array}{c}\text { Prieš PKR } \\
\text { plastiką } \\
(\text { Vidurkis } \pm \text { SN) }\end{array}$ & $\begin{array}{c}\text { Po PKR } \\
\text { plastikos } \\
\text { (Vidurkis } \pm \text { SN) }\end{array}$ & p \\
\hline $\begin{array}{l}\text { Tiriamoji } \\
(\mathrm{n}=11)\end{array}$ & $41,04 \pm 3,84$ & $42 \pm 3,65$ & $\mathrm{p}>0,05$ \\
\hline $\begin{array}{l}\text { Kontroline } \\
(\mathrm{n}=10)\end{array}$ & $40,78 \pm 3,95$ & $41,72 \pm 3,59$ & $\mathbf{p}<\mathbf{0 , 0 5}$ \\
\hline $\mathrm{p}^{* *}$ & $\mathrm{p}>0,05$ & $\mathrm{p}>0,05$ & \\
\hline
\end{tabular}

4 lentelė. Pažeistos kojos šlaunies ir blauzdos apimties rodikliai (cm) prieš ir po PKR plastikos

$\pm S N- \pm$ standartinis nuokrypis; $p^{* *}$ - reikšmingumas tarp grupiu; $p^{*}$ - reikšmingumas grupése.

\begin{tabular}{|c|c|c|c|}
\hline Grupės & $\begin{array}{c}\text { Prieš PKR } \\
\text { plastiką } \\
\text { (Vidurkis } \pm \text { SN) }\end{array}$ & $\begin{array}{c}\text { Po PKR } \\
\text { plastikos } \\
\text { (Vidurkis } \pm \text { SN) }\end{array}$ & $\mathbf{p}^{*}$ \\
\hline & \multicolumn{2}{|c|}{ Šlaunis } & \\
\hline $\begin{array}{l}\text { Tiriamoji } \\
(\mathrm{n}=11)\end{array}$ & $56,52 \pm 5,96$ & $55,73 \pm 5,81$ & $p<0,05$ \\
\hline $\begin{array}{l}\text { Kontroli- } \\
\text { nè }(n=10)\end{array}$ & $55,44 \pm 5,90$ & $54,39 \pm 5,30$ & $\mathrm{p}<0,05$ \\
\hline \multirow[t]{2}{*}{$\mathbf{p}^{* *}$} & $\mathrm{p}>0,05$ & $\mathrm{p}>0,05$ & \\
\hline & \multicolumn{2}{|c|}{ Blauzda } & \\
\hline $\begin{array}{l}\text { Tiriamoji } \\
(n=11)\end{array}$ & $39,32 \pm 3,56$ & $38,84 \pm 3,34$ & $\mathrm{p}>0,05$ \\
\hline $\begin{array}{l}\text { Kontroli- } \\
\text { nè }(n=10)\end{array}$ & $38,73 \pm 3,65$ & $37,88 \pm 4,18$ & $p<0,05$ \\
\hline $\mathbf{p}^{* *}$ & $\mathrm{p}>0,05$ & $\mathrm{p}>0,05$ & \\
\hline
\end{tabular}

Tyrime dalyvavo 3 moterys ir 18 vyrų. 12 tiriamuju buvo operuota dešinè koja, o 9 kairè. Bendra tiriamuju charakteristika pateikiama 1 lentelèje.

Tiriamieji pilde Lysholm klausimyną, skirtą subjektyvios kelio sąnario funkcijos vertinimui (1 pav.). Atsižvelgiant i balų grupes: $<65$ bloga; 65-83 patenkinama; 84-94 gera; 95-100 puiki; buvo nustatyta, kad abi grupès savo būklę prieš PKR plastiką vertino kaip patenkinamą $(\mathrm{p}>0,05)$. Praėjus mėnesiui po rekonstrukcijos abiejų grupiu klausimyno vidutiniai balai sumažejo reikšmingai $(p<0,05)$. Taip pat kontrolinès grupès vidutiniai balai buvo 9,54 mažesni nei tiriamosios, tarp grupių gautas statistiškai reikšmingas skirtumas $(p<0,05)$. Vidutiniai balai parodè, kad tiriamosios grupès būklè praejjus mėnesiui po plastikos išliko patenkinama, o kontrolinès progresavo iki blogos.

Iš 2 lentelès galima matyti, kad prieš PKR rekonstruojamąją operaciją tarp grupių skausmo rodikliai reikšmingai nesiskyrè ( $\mathrm{p}>0,05)$. Praejus mènesiui po PKR plastikos kontrolinejje grupeje skausmas padidèjo 1,1 balais $(\mathrm{p}<0,05)$, o tiriamojoje - sumažejo 0,46 balais ( $p>0,05)$. Taip pat gauta, kad tiriamoji grupe jaute 1,46 balai mažesnị skausmą nei kontrolinè $(\mathrm{p}<0,05)$. Rezultatai parodè, kad priešoperacinis mokymas ir atlikta rekomenduojamų pratimų programą namuose padeda statistiškai reikšmingai sumažinti pooperacinị skausmą.

Pirmą ménesị po PKR plastikos kelio sąnario tinimas būdingas abiejų grupių tiriamiesiams (3 lentelè). Gauta, kad po rekonstrukcijos pažeistos kojos kelio sąnario apimtis tiriamojoje grupeje padidèjo $0,96 \mathrm{~cm}(\mathrm{p}>0,05)$, o kontrolinėje pakito $0,94 \mathrm{~cm}(\mathrm{p}<0,05)$. Galima teigti, kad pacientai, kurie prieš operaciją buvo mokomi ir atlikto rekomenduojamą pratimų programą, lyginant su kontroline grupe tikimybès išsivystyti didesniam kelio sąnario tinimui po PKR plastikos neturejjo.Prieš PKR plastiką grupėse nenustatytas visiškas kelio sąnario ištiesimas ( 2 pav.), tarp grupių buvo $-0,22^{\circ}$ skirtumas $(\mathrm{p}>0,05)$. Mènuo po operacijos kelio sąnario tiesiamosios amplitudès trūkumas abiejose grupèse dar padidèjo $(\mathrm{p}<0,05)$, tačiau tiriamosios grupès vidutinè tiesimo amplitudè buvo $3,11^{\circ}$ didesnè nei kontrolinès $(p<0,05) .3$ paveiksle matoma, kad prieš PKR plastiką tarp tiriamosios ir kontrolinès grupés kelio sąnario lenkimo amplitudès buvo $2,9^{\circ}$ skirtumas ( $\left.>0,05\right)$. Po operacijos abiejų grupių kelio sąnario lenkimo amplitudè sumažejo $(\mathrm{p}>0,05)$, bet tiriamosios ji buvo $5,53^{\circ}$ didesnè nei kontrolinès grupès $(p>0,05) .4$ lentelejje pateikti šlaunies ir blauzdos apimčiu rodikliai. Prieš PKR plastiką skirtumas tarp grupių pažeistos kojos šlaunies apimčių buvo $1,08 \mathrm{~cm}$ $(\mathrm{p}<0,05)$. Mènuo po operacijos vidutiniškai apimtys tiriamojoje grupejje sumažéjo tik $0,79 \mathrm{~cm}(\mathrm{p}>0,05)$, o kontrolinèje šis pokytis buvo didesnis $-1,05 \mathrm{~cm}(\mathrm{p}<0,05)$. Tarp 
grupių skirtumas padidejo iki 1,34 cm ( $>>0,05)$. Galima daryti prielaidą, kad po PKR plastikos tiriamojoje grupejje raumenų hipotrofija vystosi lečiau.

Prieš PKR plastiką tarp grupių sveikos ir pažeistos kojos blauzdos lenkiamujjų ir tiesiamujų raumenų izometrinès jègos statistiškai reikšmingų skirtumų nebuvo $(p>0,05)(4$ pav.). Praèjus mėnesiui po PKR plastikos (5 pav.) grupèse izometrinè raumenų jèga sumažèjo $(p<0,05)$, išskyrus tiriamosios grupés sveikos kojos blauzdos tiesiamuosius raumenis (4-5 pav.). Mènuo po PKR plastikos tiriamosios grupès sveikos blauzdos tiesiamujų raumenų jèga buvo 84,65 $\mathrm{N}$ didesnè nei kontrolinès ( $\mathrm{p}<0,05)$, o pažeistos $47,17 \mathrm{~N}$ $(p<0,05)$. Lyginant blauzdos lenkiamuosius raumenis, gauta, kad sveikoje kojoje tiriamosios grupés jèga buvo 82,65 $\mathrm{N}$ didesnè už kontrolinès $(\mathrm{p}<0,05)$, o sveikos $-18,32 \mathrm{~N}$ $(\mathrm{p}>0,05)$.

Kvalifikuotas pacientų mokymas su rekomenduojama pratimų programa namuose daro teigiamą poveiki ir turi efektą funkcinių rodiklių pokyčiams po PKR plastikos. Šis tyrimas, panašiai kaip ir Dragicevic-Cvjetkovic irkt., atskleidè, kad pacientai, kurie gauna išsamų reabilitacijos programos aprašymą, lyginant su tais, kurie jo negauna, praejjus 1 , ir net 3 ir 6 menesiams po plastikos savo kelio sąnario funkcinę būkę (Lysholm) vertina reikšmingai geriau $(\mathrm{p}<0,05)$. Autoriai reikšmingus skirtumus tarp grupių gavo vertinant ir šlaunies apimtis $(p<0,05)$ [4]. Šiame tyrime reikšmingo skirtumo tarp grupių šlaunies apimčių nebuvo $(p>0,05)$, tačiau tiriamojoje grupeje hipotrofija buvo mažesnè.

Taip pat Grant su bendraautoriais ịvertino iškart po PKR plastikos pradètos ir 12 sav. taikytos namų reabilitacijos (4 susitikimai mokymams su kineziterapeutu) ir 17 užsièmimų kartu su kineziterapeutu programų poveikį, buvo gauta, kad pacientų, atlikusių namų programą, kelio sąnario lenkimo ir tiesimo amplitudès padidejo labiau $(\mathrm{p}<0,05)$ [8]. Šis didejjimas buvo stebimas mènuo po plastikos ir šiame tyrime išsamią mokymų programą gavusioje grupejje, tačiau tik kelio sąnario tiesimo amplitudè tarp grupių skyrèsi reikšmingai $(\mathrm{p}>0,05)$.

Kvalifikuotas pacientų mokymas su rekomenduojama pratimų programa namuose daro teigiamą poveikị ir turi efektą funkcinių rodiklių didèjimui ankstyvuoju periodu po PKR plastikos.

\section{Išvados}

1. Tiriamieji, kurie buvo mokomi prieš operaciją praejjus mènesiui po PKR rekonstrukcijos savo kelio sąnario funkcinę būklę vertino geriau nei tie, kurie gavo tik trumpą žodinį mokymą ir ịprastą atmintinę $(\mathrm{p}<0,05)$.

2. Tiriamieji, kurie išèjo priešoperacinio mokymo pro- gramą ir atliko rekomenduojamus pratimus namuose, po PKR plastikos jautè mažesni skausmą kelyje, turèjo labiau priartejusią prie normos kelio sąnario tiesimo amplitudę, didesnę izometrinę pažeistos ir sveikos kojos blauzdos tiesiamujų bei sveikos kojos blauzdos lenkiamujų raumenų jẻgą nei asmenys, kurie gavo trumpą žodinį mokymą ir iprastą atmintinę $(\mathrm{p}<0,05)$.

\section{Literatūra}

1. Bien DP, Dubuque TJ. Considerations for late stage ACL rehabilitation and return to sport to limit re-injury risk an maximize athletic performance. The International Journal of Sports Physical Therapy 2015;10(2):256-271.

2. Grinsven S, Cingel REH, Holla CJM, Loon CJM. Evidencebased rehabilitation following anterior cruciate ligament reconstruction. Knee Surgery, Sports Traumatology, Arthroscopy 2010;18:1128-1144.

http://dx.doi.org/10.1007/s00167-009-1027-2

3. Hewett TE, Stasi SL, Myer GD. Current concepts for injury prevention in athletes after anterior cruciate ligament reconstruction. The American Journal of Sports Medicine 2013;41(1):216-224.

http://dx.doi.org/10.1177/0363546512459638

4. Dragicevic-Cvjetkovic D, Jandric S, Bijeljac S, Palija S, Manojlovic S, Talic G.The effects of rehabilitation protocol on functional recovery after anterior cruciate ligament reconstruction. Medical Archives 2014;68(5):350-352.

http://dx.doi.org/10.5455/medarh.2014.68.350-352

5. Grindem H, Risberg MA, Eitzen I. Two factors that may underpin outstanding outcomes after ACL rehabilitation. British Journal of Sports Medicine 2015;49:1495.

http://dx.doi.org/10.1136/bjsports-2015-095194

6. Ronco M, Iona L, Fabbro C, Bulfone G, Palese A. Patient education outcomes in surgery: a systematic review from 2004 to 2010. International Journal of Evidence-Based Healthcare 2012;10:309-323.

http://dx.doi.org/10.1111/j.1744-1609.2012.00286.x

7. Malempati Ch, Jurjans J, Noehren B, Ireland ML, Johnson DL. Current rehabilitation concepts for anterior cruciate ligament surgery in athletes. Sports Medicine 2015;38(11):689-696

8. Grant JA, Mohtadi NGH. Two- to 4-year follow-up to a comparison of home versus physical therapy-supervised rehabilitation programs after anterior cruciate ligament reconstruction. The American Journal of Sports Medicine 2010;38(7):1389-1394. http://dx.doi.org/10.1177/0363546509359763

\section{EFFECT OF PREOPERATIVE EDUCATION ON PATIENT'S AFTER CRUCIATE LIGAMENT RECONSTRUCTION FUNCTIONAL STATUS A. Vainiūtè, I. E. Jamontaitè}

Key words: anterior cruciate ligament reconstruction, education, functional status. 
Summary

The aim of research is to evaluate the impact of preoperative education of patients functional status after anterior cruciate ligament plastic (ACL). The research included 21 patients (age 32,9 $\pm 9,99$ years). They were randomly divided into two groups: an experimental group to which a comprehensive preoperative training was applied and a recommended home exercise program was given and a control group which received a brief oral training and an ordinary memory note. Measurement of clinical indicators was carried out the day before the ACL plastic and a month after. The data was calculated applying the Stjudent's ( $t$ ) criteria, significance level $\mathrm{p}<0.05$. A month after ACL plastic both groups functional status deteriorated, but the experimental group's subjective knee joint condition, extension and flexion amplitude, pain, swelling, thigh and calf muscles hypotrophy, isometric calf flexural and extensor muscle strength evaluation results were better than these of the control group.

Correspondence to: aistei.vainiutei@gmail.com

Gauta 2016-06-09 